\title{
Journal of the American Medical Association.
}

EDITED UNDER THE DIRECTION OF THE BOARD OF TRUSTEES.

PUBLISHED WEEK LY.

Vol. XII.

CHICAGO, APRIL, 27, 1889.

No. 17 .

\section{ORIGINAL ARTICLES.}

POPULAR FALLACIES REGARDING ATHLETES AND ATHLETICS.

BY IRVING ROSSE, M.D., OF WASHINGTON, D. C.

As a branch of medicine that has for its object the bringing of man to a greater state of physical perfection, the question of athletics has for the more advanced and liberal minded of our profession the highest interest.

In our parliamentary city where so many persons suffer from the effect of sedentary life, the athletic remedy seems to be the only sensible one, and it is daily becoming more apparent that a growing demand for athletics exists among the bright young men of the civil service who are fast replacing the sick, the infirm, and the political paretics that formerly filled the government departments. It is, therefore, with much gratification that we can point to the organizations of the Columbia Athletic Club of $45^{\circ}$ members, and note the very favorable auspices under which it takes departure, owing to the liberality of a wealthy citizen, Mr. John McLean, formerly of Cincinnati.

The War Department, too, shows increased concern in the somatic efficiency of the material composing the Army. Dr. Greenleaf, of the Surgeon-General's office, has lately interested himself in the study of Dr. Sargent's anthropometric system with a view to its general introduction into the service. Any measure that will raise the physical standard in our little army is, of course, worthy of the highest praise. Even West Point men are physically far below the popular conception. A large proportion of them cannot swim, and generally speaking, the educational means of elevating the physical powers are not at the Military Academy what they should be. Acute indigestion and affections of the alimentary canal are more common than is generally supposed among the cadets, and inability to support a little fatigue and atmospheric vicissitude, such as that encountered at the inauguration of General Grant in March, 1873, does not give a very favorable exhibit, judging from the sick reports of that month, which shows a total of
I95, while a larger number of artillerymen, nearly all of whom got wet the night before the inauguration, shows but thirty-three sick. The proportion of sick among the naval cadets, also present, was notably less-a circumstance that speaks well for the reorganization of Admiral Porter, who, by the way, has correct and enthusiastic notions in regard to physical culture, which have been introduced at the Academy. To any one witnessing the parade on the forementioned occasion the fresh, ruddy appearance of the midshipmen was in striking contrast to that of the cadets. A few years since at the Artillery school at Fort Monroe, of fifty-three officers, mostly young graduates, only eight could swim, and but three well; three more knew a little about boxing, and two could put up the dumb bell of sixty pounds-facts that go to show that military drill alone is a poor means to attain the athletic habit of body so becoming to a soldier.

Aside from military considerations, it may be laid down as an axiom, that in order to have a strong nation the palestric element must enter. Many popular fallacies concerning athletes and athletics still prevail to a great extent, not only in the general community, but among medical men, and this mainly for the reason that heretofore most of the published opinions relatively thereto have emanated either from athletes who knew nothing of medicine, or from physicians who were not athletes. In these days when errors are being dispelled and the mists of prehistoric times are finally rolling away, a thoughtful man is often astonished at the persistency of many popular fallacies, which, as a matter of fact, are no better than the groundless superstitions about Friday, thirteen at table, or the alleged coincidence of the red-headed girl and the grey horse - all of which exemplifications may be classed in the same category of sophistical reasoning with much that has been written and accepted respecting athletics.

Physicians are often accused of their deficiencies in the science of logic, and in many instances very justly so, but I am not at all prepared to believe that as a class they are any more deficient in this respect than other people. Without attempting to take up their cause, I will admit that the records of medical literature are 
filled with rubbish, and that medicine continues to deserve the designation of an art rather than that of a science, mainly for the reason that some medical men will rush into print with no suggestion as to the insufficiency of the evidence adduced in order to establish a new truth. This gives rise to that common and most fatal of all errors, a post-hoc conclusion. If I were writing a book on errors in reasoning, and wanted to exemplify false ratiocination or deduction, I do not know of a more prolific source than that of sciolistic medicine, from which I might borrow pathological illustrations so to speak.

I might also quote various authors who, in regard to physical exercises, have carried their invectives so far as to have substituted prejudice for reason, and have generalized from insufficient observation.

Mr. Wilkie Collins' attempt to bring athletics into disrepute in "Man and Wife" is but a vulgarization of the professional opinion held and promulgated by many physicians; and it needs but a superficial acquaintance with current medical literature, to find the most unqualified condemnation of athletics, and the warnings against their evil consequences.

One writer says they cause hernia and aneurism, another heart disease, while a third asserts that athletes soon grow stale and are short lived. These, with many other alleged hurtful consequences have been put forward with all the pretension of spectacled gravity to give them currency. It is easy to understand from what point of view Mr. Collins regards athletics. Being a small, round shouldered man, with a shambling gait, it is not surprising that his connotation should assume something of a lame man's opinion of dancing, but observation and experience do not justify the deductions of physicians who stigmatize athletics. I have known many hundreds of athletes in different parts of the world, and I have yet to learn of more than one case of hernia resulting from over-exertion. The mechanical impossibility of producing a hernia on a dead body, even if the abdomen be forcibly compressed, if gaps be made in its walls, and the belly subjected to several hundred-weight, and even to horse-power, would seem to demonstrate that hernias do not originate from violent muscular efforts, but are already present, being generally congenital.

Concerning the prevalence of aneurism and heart disease among athletes, there are many current errors that reflect the common judgment. A noted athlete dies of heart trouble, phthisis or paralysis, upon which popular judgment, and regretable to say, the unthinking medical man draw a post-hoc conclusion. It requires but little thought to upset this fallacy.

Athletes, as a class, are not short lived. On the contrary, many who have led sober and regular lives have attained extreme old age. It is hardly necessary to refer to the historical mention of Socrates, who at the age of 60 , an age when officers of the Army and Navy are retired, served as hoplite in the Peloponnesian war, and though covered with heavy armor took upon his shoulders a wounded man whom he carried into camp while being pursued by the enemy.

In England the general impression among many is that the occupation of pugilist, instead of being hurtful, is a remarkably healthy one, and it is generally admitted that they live longer than any other men. This assertion is supported by facts that are recognized and commented upon by Dr. Royer-Collard in his celebrated work on Organoplastie Hygiènique. We have numerous instances of old athletes who have not become stale. Many persons have heard of old Gabe Ravel, who at a very advanced age, turned back sommersaults. Frenchmen also know of Madame Saqui, who at the age of 70 , in Paris, walked a wire stretched at a great height. Circus men are not only healthy, but long lived. The famous clown of London, Joe Wallet, was ten years ago considerably over 70 , and as lively and active as he was forty years previously. Old Orde lived to considerably over 90 , and a short time before his death, gave bareback performances. Batty was in the business till past 70, and Franks some years since was tumbling somersaults and posturing at Hengler's considerably over 60 , and as fresh as a daisy. An inquiry extending over more than fifty years shows that the men who rowed in the Oxford and Cambridge crews lived on an average longer then the men who did not row. The former champion Greco-Roman wrestler, William Miller, informs me that he knows of many athletes who have attained a good old age, and his opinion, the one held generally by professionals, is that the proper employment of athletics united to a regular life is highly conducive to longevity. Mr. Phineas T. Barnum tells me that he considers the exercises of a well conducted circus to be of the most healthy character, developing the performers chiefly into muscle, and making them the most vigorous people living. As a class, they are long lived, in fact more so than persons in ordinary occupations, especially when they have been temperate. Among very old English pugilists may be mentioned Belasco, Adams, and the older Stevenson. A few years since the sporting papers recorded the death, at an advanced age, of Owen Swift, whose extraordinary career as a prize fighter, may be seen in the musty old files of fifty years ago, he then being in the thirties, while Tom Sayers was still in swaddling clothes, and had already killed one man before Jem Mace was born. Some time since the death of Bendigo, who passed from the prize ring to the pulpit, was reported at 68 years; and during the last year 
two other noted pugilists have died at advanced age. One of them, Jem Ward, born in London on Christmas day, I800, was perhaps the oldest boxer in the world. Most New Yorkers can re. call Ottignon and "Pop" Whittaker in this connection. I know yet of an old man of 75, who still puts up bis hands in a surprising manner and, barring eye sight, is well preserved.

A few years since, in San Francisco, I was walking in the street with the Secretary of the Olympic Club, who talked to me of this very matter, when we came across a very old man, whom he pointed out as a corroborative instance of what he was telling me. This man in days gone by, had been an athlete of the most violent kind, in fact, a man who had misused athletics by such feats as walking a thousand miles in a thousand hours and other like senseless performances.

The untimely death of several notables who have figured extensively in the athletic world during the last fifteen or twenty years, has, in every instance, as far as could be ascertained, been owing to preventable or to immoral causes, the nature of which it is not necessary here to specify. The possibility of over-exertion being the catuse of impaired health in after-life is exceedingly problematical.

The result is rather owing to immoderate indulgence and to the neglect of simple hygienic rules. It is, of course, possible for one to abuse and overdo physical exercise, just as one may do by eating too wuch bread and thereby poisoning oneself; but enlightened common sense would say that in a misuse of this kind, it is the man, not the bread or the athletics that should bear the blame.

On this subject, Dr. Sargent, of Harvard, tells me that he thinks it but fair to state that in many instances the early demise of athletes cannot be directly attributed so much to the results of athletic work as to the free indulgence of gross appetites and passions which they have not the moral power to control, and where this was not the case, they lived beyond the average. From extensive personal knowledge he knows of but two deaths attributable to over-exertion; the others were from dissipation, and its train of attendant evils. Inquiry seems to establish the fact that the occupation of athletics is more favorable to longevity than many of the mechanical and industrial pursuits, notably those of shoemaker, tailor, baker, clerk or miner; and if further trust may be placed in vital statistics, merchants, capitalists, financiers and persons engaged in the transfer of property have not the same lease of life.

I have now put in light a sufficient number of facts the very opposite from those of other observers, who seem to have limited their sphere of action to but one side of the question.
My collection of facts may be wanting in delicate analysis, and the homogeniety and regularity indispensable to science; but the observation of such as $\mathrm{I}$ have brought forward, even when observed without the aid of method, forces upon us the induction that no good reason exists for the wholesale condemnation of athletics. On the contrary, it is evident that the bealthy exercise of the physical powers, is one of the necessary pastimes of a manly and vigorous race; and that next to food and sleep athletics has the largest share in the recreation of human life. It is, therefore, high time that the conventional opinion of certain medical men and of some educators on this subject should be set aside, and that all the manly sports should be encouraged, and fostered with a view to promote qualities that intimately concern not only the happiness and usefulness of individual life, but also the good of society, and the future of the human race.

SCARLATINIFORM RASHES.

Read before the St. Louis Medico-Chirurgical Society, Oct. $30,1888$.

BY JOSEPH GRINDON, M.D.,

LECTURER ON DISEASES OF THE"SKIN AT THE ST. LOUIS MEDICAL COLLEGE.

There is made no claim of originality for this paper, as it consists simply in a re-arrangement of what is to be found in the text-books and current literature of the day. My object has been to group together in this form those erythemata and other diseases of the skin which may by their resemblance to scarlet fever lead to errors of diagnosis, believing that the setting of old truths in a new light is not devoid of benefit.

The early roseola of syphilis may somewhat resemble scarlatina, especially when attended with throat complications and syphilitic fever. It is not necessary to do more than allude to the possibility of mistake here.

It was long since noted, by Sir James Paget, that the wounded are specially predisposed to scarlet fever. This was confirmed later by many eminent French and English observers. Mr. Holmes, while admitting the fact, contended that many so-called cases of "surgical scarlet fever" were really due to septicæmia or pyæmia, to the absorption of some other than the true scarlatinous poison. I believe that the predisposition above spoken of, and also the existence of a scarlatiniform septicamic rash, are now admitted on all sides, but there seems still to be considerable difference of opinion as to the relative prevalence of the two.

The appearance of a scarlet rash in a puerperal woman gives scope for the exercise of one's diagnostic powers. The date of delivery marks a change in the receptivity of woman for the contagious diseases. The pregnant female is less, 